\title{
EDITORIAL
}

\section{HPV infection in children, astrometry and the end of a Greek legend}

\author{
IOANNIS N. MAMMAS ${ }^{1-4}$, CHRYSSIE KOUTSAFTIKI ${ }^{5,6}$, \\ ALEXIA PAPATHEODOROPOULOU $^{7}$ and DEMETRIOS A. SPANDIDOS ${ }^{1,3}$ \\ ${ }^{1}$ Institute of Paediatric Virology; ${ }^{2}$ Paediatric Clinic, Aliveri, 34500 Island of Euboea; \\ ${ }^{3}$ Laboratory of Clinical Virology, Medical School, University of Crete, 71003 Heraklion; \\ ${ }^{4}$ First Department of Paediatrics, University of Athens School of Medicine, 11527 Athens \\ ${ }^{5}$ COVID-19 Reference Centre, 'Rafina' Health Care Centre, 19009 Rafina; ${ }^{6}$ Paediatric Intensive Care Unit (PICU), \\ 'Penteli' Children's Hospital, 15236 Palaia Penteli; ${ }^{7}$ Paediatric Intensive Care Unit (PICU), \\ University Hospital of Patras, 26504 Rio, Greece
}

Received July 31, 2020; Accepted October 24, 2020

DOI: $10.3892 /$ etm.2020.9429

'It is particularly important for young paediatricians to have a good knowledge of the field of Virology'

Harald zur Hausen

In 1956, a Greek author named Menealos Lountemis (1912-1977) published his book entitled 'A child is counting the stars' (1). This autographic book approaches the issue of children's rights for equal opportunities in education and is one of the most popular children's novels in Greece to date. The child, who "counts the stars', Melios Kadras, makes his dreams come true having as his only weapon his passion for learning. Nevertheless, Greek folk tradition has related the counting of the stars, a favorite habit of children in the Greek countryside during the moonless dark summer nights, to the development of skin warts $(2,3)$. This relationship is described in a very touching Greek legend, with several forms in different geographical areas and islands in Greece, where, when children count the stars, skin epithelial lesions are developed usually in their fingers that point the stars. Interestingly, these lesions are tiny and resemble the stars' spots in the night's sky. In Crete, an island, where the fifteen-syllable rhyming couplets, known as 'mantinada', express the folk wisdom in a unique Doric manner, a relevant wise 'mantinada' from Pefkos, Viannos, in South Crete, states:

Correspondence to: Dr Ioannis N. Mammas, Paediatric Clinic, Aliveri, 34500 Island of Euboea, Greece

E-mail: mammasjo@googlemail.com

Professor Demetrios A. Spandidos, Laboratory of Clinical Virology, Medical School, University of Crete, 71003 Heraklion, Greece

E-mail: spandidos@spandidos.gr

Key words: HPV, Paediatric Virology, Institute of Paediatric Virology, medical education, Harald zur Hausen
'Look up in the sky, but don't count the stars, because skin warts will suddenly appear on both of your hands!'

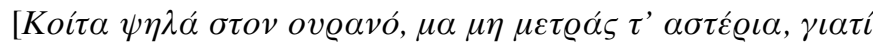

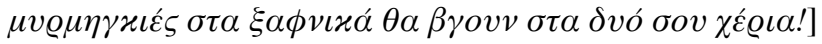

To date, it is known that children's skin warts are the result of a viral infection and the causative agents of this infection are human papilloma viruses (HPVs). Children counting the stars during the summer nights are vulnerable to the skin-to-skin transmission of HPVs and their skin warts are not related to astrometry! Research on HPV by the 'Father of HPV Virology', Professor Harald zur Hausen, explained in detail the causative role of specific types of HPVs in children's warts (4), as well as of other types of HPVs in human cervical carcinogenesis (5). His explanation, though, led to the unexpected end of our childhood Greek legend.

Professor Harald zur Hausen is a great benefactor of the Paediatric Virology Study Group (PVSG) and the newly founded Institute of Paediatric Virology based on the island of Euboea in Greece (6). Our meeting in Heidelberg in 2014 was the crucial point of the PVSG's aim to initiate the 'workshops on paediatric virology', aiming to bring together paediatric trainees and paediatricians with virologists (Fig. 1). In October, 2017, his clear messages in the context of the '3rd workshop on paediatric virology' on the role of human breast milk feeding in the prevention of viral infections, as well as the necessity of male vaccination against HPV, highlighted the great significance of his outstanding contribution to the constantly growing educational challenge of paediatric virology (7-9). In September, 2018, PVSG had the opportunity to discuss the future of medical education in paediatric virology with him. All these years, our scientific efforts have been based on his high-level scientific ideals related to evidence based-medicine, dedication and humani- 


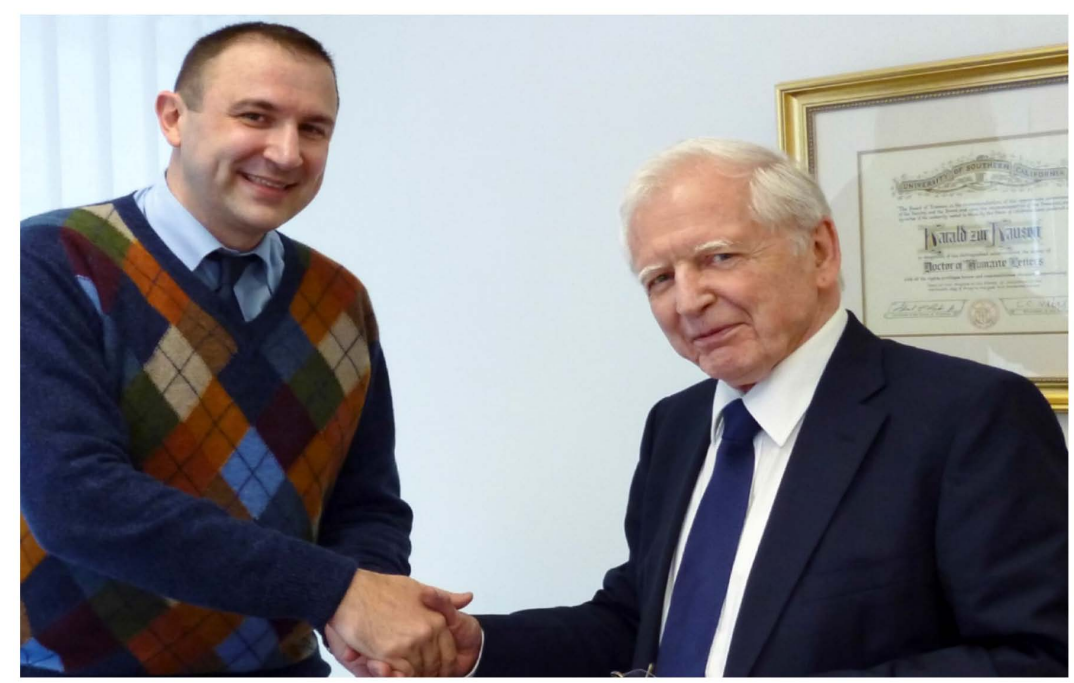

Figure 1. 2014. Dr Ioannis N. Mammas, Consultant Paediatrician and Coordinator of the Paediatric Virology Study Group (PVSG) with Nobel Laureate Professor of Virology Harald zur Hausen in Deutsches Krebsforschungszentrum in Heidelberg, Germany (Photo by Mrs. Marie-Luise Braun).
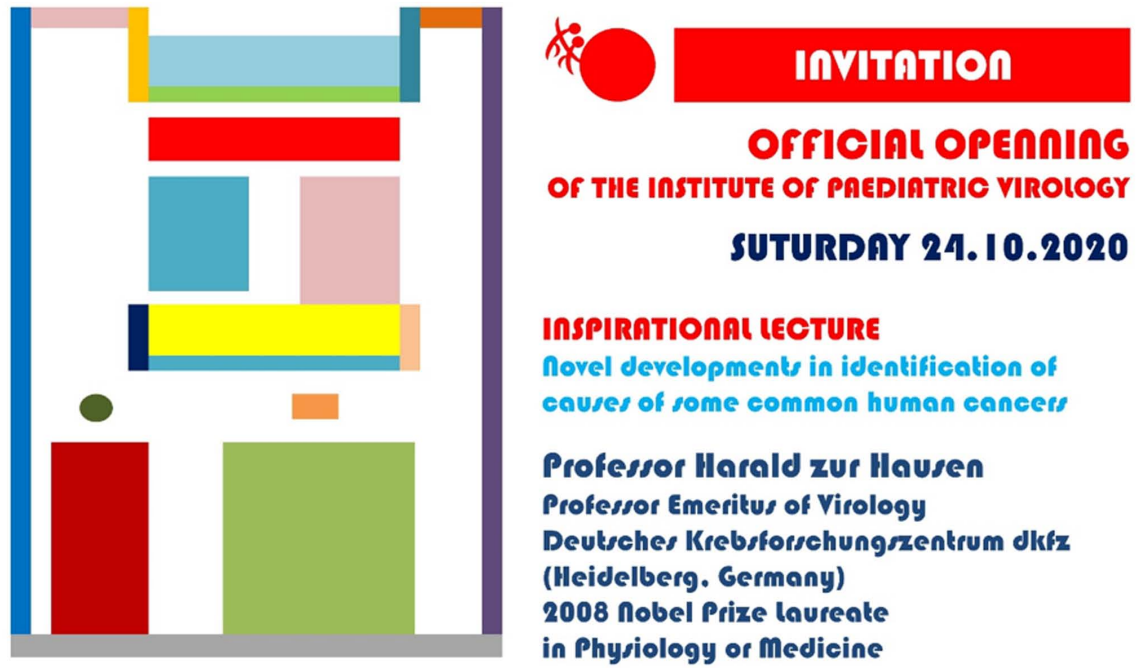

\section{INSPIRATIONAL LECTURE}

novel developments in identification of causes of some common human cancers

\section{Professor Harald zur Hausen \\ Professor Emeritus of Virology \\ Deutsches Krebsforschungrzentrum dkfz \\ (Heidelberg. Germany) \\ 2008 nobel Prize laurente \\ in Physiology or medieine}

Figure 2. 2020. The invitation of Professor Harald zur Hausen's inspirational lecture in the context of the official opening of the Institute of Paediatric Virology based on the island of Euboea in Greece.

tarianism. Professor Harald zur Hausen has received the '2016 George N. Papanicolaou Humanitarian Award' and the '2017 Paediatric Virology Award' for his humanitarianism and his outstanding academic, clinical, research and publishing contribution to medicine and paediatric virology.

In the context of the forthcoming official opening of the Institute of Paediatric Virology Professor Harald zur Hausen's inspirational lecture will focus on 'novel developments in identification of causes of some common cancers' (Fig. 2).

\section{Acknowledgements}

This article is published in the context of the foundation of the Institute of Paediatric Virology (IPV; https:// paediatricvirology.org) based on the island of Euboea (Greece), under the auspices of the World Academy of Sciences (WAS) and the support of the Department of Clinical Virology of the University of Crete School of Medicine and the First
Department of Paediatrics of the University of Athens School of Medicine. We would like to thank all the members of the IPV for their valuable comments and corrections.

\section{Funding}

No funding was received.

\section{Availability of data and materials}

Not applicable.

\section{Authors' contributions}

All authors (INM, CK, AP and DAS) contributed equally to the conception and design of this manuscript, wrote the original draft, edited and critically revised the manuscript, read and approved the final manuscript. 


\section{Ethics approval and consent to participate}

Not applicable.

\section{Patient consent for publication}

Not applicable.

\section{Competing interests}

INM and DAS are Co-founders of the Institute of Paediatric Virology (IPV). CK and AP declare that they have no competing interests. DAS is the Editor-in-Chief for the journal, but had no personal involvement in the reviewing process, or any influence in terms of adjudicating on the final decision, for this article.

\section{References}

1. Lountemis M: A child is counting the stars. Dorikos, Athens, 1956 (In Greek).
2. Magkoutas I: Folklore from the village Theologos in the island of Euboea. Third Part. Arch Euboean Stud 36: 207-234, 2005-2006.

3. Zacharioudakis F: Precautions and superstitions over the years in Crete. Cretan Magazine, 2017. www.cretanmagazine.gr.

4. Pfister $\mathrm{H}$ and zur Hausen $\mathrm{H}$ : Seroepidemiological studies of human papilloma virus (HPV-1) infections. Int J Cancer 21: 161-165, 1978.

5. zur Hausen H: Papillomaviruses and cancer: From basic studies to clinical application. Nat Rev Cancer 2: 342-350, 2002.

6. Mammas IN, Greenough A, Theodoridou M and Spandidos DA The foundation of the Institute of Paediatric Virology on the island of Euboea, Greece (Review). Exp Ther Med (In Press).

7. Mammas IN and Spandidos DA: Athens-based meeting to discuss the paediatric virology crossroad in October 2017. Acta Paediatr 106: 1536, 2017.

8. Mammas IN and Spandidos DA: Paediatric Virology as a new educational initiative: An interview with Nobelist Professor of Virology Harald zur Hausen. Exp Ther Med 14: 3329-3331, 2017.

9. zur Hausen H, Mammas IN and Spandidos DA: HPV vaccination in boys: Determining the clinical relevance of this strategy. Exp Ther Med 14: 3327-3328, 2017.

This work is licensed under a Creative Commons Attribution-NonCommercial-NoDerivatives 4.0 International (CC BY-NC-ND 4.0) License. 